\title{
Learning from Ontario's municipal drug strategies: an implementation framework for reducing harm through coordinated prevention, enforcement, treatment, and housing
}

\author{
Anthony Piscitelli*
}

\begin{abstract}
Since 2001, when Vancouver completed its integrated drug strategy, other Canadian municipalities have begun to explore their role in addressing addictions issues. This article reviews reports from ten municipal drug strategies written in the Canadian province of Ontario to develop recommendations for practitioners wishing to implement their own drug strategy. Note that this paper's focus is on implementation, and it does not seek to evaluate the underlying clinical practices involved in such strategies. All published reports from 10 municipal drug strategies in Ontario released between 2005 and 2015 were read and analyzed using thematic analysis. Similarities are found between the different strategies approaches to data gathering, the vision statements, the mission statements, and the principles of service. Each municipality was also found to focus on four pillars: prevention, treatment, enforcement, and harm reduction. Some municipalities added an additional pillar: integration, sustaining relationships, or housing. These pillars were used to frame the strategies recommendations. Ten questions for municipalities to consider in their own drug strategy consultations are recommended.
\end{abstract}

Key Words Drug strategies; municipalities; addictions issues.

Journal of CSWB. 2017 June;2(2):58-62

www.journalcswb.ca

\section{INTRODUCTION}

In 2001, Vancouver completed the first integrated drug strategy in Canada (MacPherson \& Rowley, 2001). Since that time, municipalities across Canada have begun to explore their role in addressing addictions issues through their own integrated drug strategies.

The Vancouver Drug Strategy applied a Four Pillar approach to addressing substance use issues in cities. The four pillars of prevention, treatment, enforcement, and harm reduction provided a framework to help focus resources and coordinate efforts to address problematic substance use (MacPherson \& Rowley, 2001; Macpherson, Mulla, Richardson et al. 2005). The integration of Harm Reduction was a new approach in Vancouver, and Canada (Alexander, 2006).

Grassroots activism efforts led to the Vancouver Drug strategies development. "Nothing would have happened in Vancouver had there not been drug users putting pressure on the local health authority" (Osborn \& Small, 2006, p. 70). The efforts of these drug users were facilitated by access to a member of the Vancouver Health Board who faced addictions issues and the Vancouver Area Network of Drug Users. Ultimately, they were successful in pressuring the City of Vancouver into creating a drug strategy and in creating a template for other Canadian municipalities to follow in creating their own drug strategies.

MacPherson et al. (2006) focus upon the role that municipalities have to play in addressing drug related issues. They argue cities can focus on seven roles to prevent and reduce harm from problematic substance use. Cities can provide support for vulnerable populations directly, facilitate services for those in need, encourage dialogue and communication, build capacity, advocate to other orders of government, regulate issues, and act as a role model. These seven approaches were seen as central elements to the Vancouver Drug Strategy.

Recognizing the benefits of municipal drug strategies, the Federation of Canadian Municipalities (FCM) released a series of reports outlining some basic principles to guide drug strategy planning efforts (Federation of Canadian Municipalities, 2000; Federation of Canadian Municipalities, 
n.d.). The FCM suggests the focus of municipal drug strategies should be on illegal drugs, alcohol, and abuse of prescription drugs. This focus implicitly excludes tobacco, a legal drug in Canada. The Vancouver Drug Strategy took a similar approach focusing on illegal drugs, alcohol, and prescription drugs, but they also included some recommendations related to tobacco use.

The FCM does not explicitly focus on the four pillars; instead, it suggests a focus on three areas-prevention, rehabilitation and law enforcement-with an emphasis on "evidence-based decision making, harm reduction, and concentrated efforts at reducing both the demand and supply of illicit drugs" (FCM, 2000, p. 1). This language is not an exact match to the Vancouver Four Pillars, but prevention and law enforcement line up perfectly. Rehabilitation is quite similar to treatment and harm reduction is cited as worthy of emphasis.

The FCM suggests, in Municipal Drug Strategies in Canada, five key principles for municipalities to incorporate when developing a municipal drug strategy. They are: building on community assets, focusing on evidence based decisionmaking and on-going monitoring, having a flexible strategy, enduring municipal leadership of the planning process and implementation, and beginning strategy development with a needs assessment.

This review seeks to categorize the common elements in a sample of municipal drug strategy reports from the Canadian province of Ontario created between 2005 and 2015. Other municipalities can use this data to identify trends worth considering as they create their own drug strategies. In addition, a template of ten questions is provided for use in the research and planning phases of drug strategy development.

\section{Method}

A list of drug strategies was identified by searching the Municipal Drug Strategy Co-ordinator's Network of Ontario website. This website, as of August 17, 2016, lists nine Ontario municipalities that share their drug strategy documents on the Internet: Kenora, North Bay, Peterborough, Thunder Bay, Toronto, Waterloo Region, ${ }^{1}$ Wellington-Guelph, ChathamKent Drug, and Halton. The search for municipal drug strategies was restricted to Ontario, as this work was initially prepared to help inform the drug strategy for the City of Brantford, Ontario.

A Google Internet search was conducted focused upon the key words 'drug strategy' and the names of the municipalities listed on the Municipal Drug Strategy Co-ordinator's Network of Ontario website. Each of these municipalities had at least one report related to a drug strategy. In total, 14 reports were found related to a drug strategy and the municipalities listed on the Drug Strategy Co-ordinator's Network of Ontario website (Chang-Yen Phillips, Cockburn, Kidd et al., 2011; City of Toronto, 2005; Janzen, 2013a; Janzen, 2013b; Kenora Substance Abuse and Mental Health Taskforce, 2015; Peterborough Drug Strategy Committee, 2012; Pierce, 2008; Region of Halton, 2014; Saad, 2013; Thunder Bay Drug Strategy Committee, 2011; Thunder Bay Drug Strategy Committee, 2013; United Way of Chatham-Kent, 2009; Waterloo Region Crime Prevention Council, 2011; Wellington Guelph Drug

\footnotetext{
1 I was involved in data gathering for the Waterloo Region drugs strategy,
} but I did not participate in writing the final report.
Strategy Committee, 2011). For Halton, the only report found focused upon the need to create a local drug strategy. In addition to these documents, the Community Drug Strategy for the City of Greater Sudbury (Sudbury \& District Health Unit, 2015) was found after being referenced in documents related to the Peterborough and Waterloo Region drug strategies. This was the only additional strategy found on the Internet, despite searching for a number of other municipalities mentioned in the reports.

The drug strategy reports were read and analyzed to identify some general common elements; Background Reports, Vision Statements, Mission Statements, Principles of Service, Pillars, and Recommendations. Comparisons were made within each of these categories. First, the data gathering approaches were listed and examined for common elements. Next, the Vision Statements, Mission Statements, Principles of Service, and Pillars were each listed and compared to one another. Finally, each of the Recommendations were listed and classified, using an open coding scheme, into categories examining their focus. Halton's introductory report, "Counting, Caring, Growing: Laying the Foundation for a Halton Drug Strategy", was reviewed where appropriate.

\section{Results}

\section{Data Gathering}

Data gathering strategies were reviewed for each of the municipalities. The strategies had five basic approaches to gathering data: reviewing local data, community forums, surveys, focus groups, and interviews. All of the strategies reviewed existing local reports and/or local statistical data related to issues such as rates of local drug use and police statistics related to drug use. In addition, every municipality, except for Peterborough, hosted at least one community forum where service providers and/or members of the general public could offer their input into the strategy. Six municipalities conducted focus groups. These focus groups typically had separate sessions for service providers and individuals who use problematic substances. Finally, interviews were conducted by Guelph-Wellington, Thunder Bay, and Peterborough. Guelph-Wellington and Thunder Bay were the only two plans to incorporate all of the datagathering approaches.

\section{Vision, Mission, and Principles of Service}

The framing of the drug strategies, in all 10 of the municipalities studied contains a vision statement. These vision statements all focused on the community as a whole by referencing the name of the local city, discussing helping all citizens or specifically using the word 'community' or 'communities'. The idea of creating a healthier, safer city with improved well-being is mentioned in eight of the ten vision statements. Six vision statements mention reducing or eliminating harm within the community. Finally, three municipalities contain the words 'individuals', 'families', and 'neighbourhoods'.

Six out of the ten municipalities also included a mission alongside the vision statement. These mission statements outlined a general purpose for the drug strategy. Amongst the municipalities that did not include a mission statement, three used 'goal statements' to perform a similar function. 
The six mission statements and goal statements were compared to one another and analyzed for themes. Four of the mission statements focused on the purpose of developing and/or implementing the drug strategy. In contrast, the Kenora mission statement had three goal statements discuss improving community health. The Waterloo Region mission statement and three goal statements discussed directly address problematic substance use. In addition, two of the three goal statements noted the mechanisms of implementing the Drug Strategy, such as coordination and monitoring.

Principles of service were listed for eight of the municipalities reviewed. In addition, Guelph had five values, which were very similar to the other municipalities guiding principles. Municipalities with principles of service had between six (Thunder Bay) and thirteen (Toronto) principles; the average was 8.9. The principles of service and values were reviewed to find reoccurring principles. North Bay's report was the only one not to include principles of services.

Amongst the nine municipalities analyzed, the most common principle of service, used by all nine municipalities, was collaboration and/or partnership. This principle was typically explained as a commitment to multiple agencies, sectors and levels of government working together. Eight municipalities listed evidence-based or evidence-informed. This principle focused on ensuring that recommendations were supported by research, science, and evidence, as opposed to being based on ideology. Six municipalities mentioned innovation. This principle focused on encouraging new and creative solutions.

Four municipalities mentioned relevancy or locally relevant, inclusion, accessibility, diversity, participation, and determinants of health or underlying risk factors. Relevancy or locally relevant focused on meeting the needs of local communities and individuals who use substance. Inclusion focused on meeting the needs of all people and involving a wide variety of stakeholders in creating solutions. Accessibility focused on addressing systems barriers and promoting universal access to programming. Diversity focused on acknowledging the existence of diversity and incorporating that diversity into the strategy. Participation focused on involving people with lived experience and the community as a whole in creating the strategy. Determinants of health or underlying risk factors focused on ensuring the strategy addresses the root causes of addition and the range of factors that influence overall health.

Three municipalities mentioned socially just, sustainability, and respect. Four principles were mentioned by two plans. These were comprehensive, acceptance, balance, and compassion. Ten principles were only mentioned by one plan. These were client-centred, realistic, legal context, resiliency, building assets, promote health, transparency, accountability, open dialogue, integrity, and prevent and reduce harmful outcomes.

\section{Pillars}

The Vancouver Drug Strategy built its plan upon a framework of four central pillars: Prevention, Treatment, Enforcement and Harm Reduction. Prevention recommendations focus upon stopping the use of drugs altogether or delaying their use. Treatment focuses on interventions for individuals who face problematic substance use issues. These interventions focus on improving their health and well-being. Enforcement focuses upon the criminal justice system's responses to the use of illegal drug use. Harm Reduction focuses upon reducing the negative consequences of drug use.

The ten municipalities examined framed their drug strategy work and recommendations as falling into four or five pillars inspired by the Vancouver approach. Six of the strategies had four pillars-Prevention, Harm Reduction, Treatment and Enforcement, paralleling Vancouver's plan. Waterloo Region and Greater Sudbury each added a pillar focused upon collaboration to implement the strategy. Waterloo Region called this pillar 'Integration' and it focused upon ensuring "the final strategy is integrated, comprehensive and coordinated" (Waterloo Region Crime Prevention Council, 2011, p. 13). Greater Sudbury called their pillar 'Sustaining Relationships'. It focuses on "the development of partnerships between the community, sector organizations, and all levels of government" (Sudbury \& District Health Unit, 2015, p. 8).

Kenora and Thunder Bay each added 'Housing' as a pillar to their approach. Though only these two plans specifically cited housing as a pillar, it was an element of each of the strategies reviewed, as every plan mention housing in at least one recommendation.

\section{Recommendations}

The recommendations from the nine Ontario municipalities who have completed reports outlining their drug strategies were reviewed and analyzed for commonalities. The drug strategy recommendations focused primarily on ten areas: broad general recommendations, the plan implementation infrastructure, municipal recommendations, changes to existing programs, the introduction of new programs, research, promotional campaigns, training, recommendations for changes to the approach of municipal police, and recommendations to lobby provincial and/or federal levels of government.

Every plan contained broad general recommendations focused on overarching non-specific recommendations like improving partnerships in the community, providing more funding, supporting the philosophy of harm reduction, providing flexible service delivery, engaging with different sectors, and expanding services generally.

The recommendations typically discussed the plan implementation infrastructure by referring to the need to set up a coordinating committee, the need for funding, the need for a plan coordinator, and the need to develop an implementation work plan. Recommendations related to the plan infrastructure were contained in every plan except North Bay's.

The municipal recommendations were only contained in five of the plans. These recommendations looked at specific policy changes, such as changing housing applications, or general broad recommendations directed at cities, such as developing a community youth strategy.

The changes to existing programs and the introduction of new programs were a component of every plan. The changes to existing programs tended to focus on specific tweaks to programs, such as adding on-site childcare for treatment programs, or the expansion of existing programs to meet 
the needs of additional clients. Many changes to existing programs also focused on improving needle exchange programs to improve their effectiveness. Some changes were also suggested for how school boards discipline students for using illegal drugs.

A number of new programs were discussed as being needed by different municipalities. New programs mentioned included a methadone treatment program, a withdrawal management program, a safe bars program, and a managed alcohol treatment program. Recommendations about new programming also discussed increasing treatment options, providing mobile outreach, creating a situation table, and offering new case management services.

Every municipality, except North Bay, included researchrelated recommendations. These recommendations discussed conducting environment scans to identify gaps and assets in the community, exploring the capacity or need for specific new programs, evaluating the drug strategy itself, evaluating programming locally, and exploring best practices.

Promotional campaigns were discussed in every drug strategy reviewed, but the specific campaign suggestions varied in their focus. Many campaign recommendations focused on prevention messages; some looked at increasing support for harm reduction and reducing stigma associated with addictions; and others focused on increasing awareness of treatment options.

Training was mentioned in the recommendation for six of the plans reviewed. These recommendations discussed providing general training about addictions, making changes to the training provided to post-secondary students, expanding training about addictions issues to a variety of sectors, and engaging people with lived experience to assist in offering substance use training.

The recommendations for changes to the approach of municipal police were contained in all of the plans, except North Bay's. These recommendations focused on drug-driving issues, how police enforce drug crimes, and how police collaborate with other agencies.

The drug strategies reviewed varied significant in their treatment of lobbying provincial and federal levels of government. Three plans did not include any recommendations in their strategies related to other levels of governments. Kenora included two recommendations to other levels of government. Three plans contained between 17 and 23 recommendations directed at the provincial and/ or federal levels of government. Thunder Bay had the most recommendations directed at other levels of government, with 31 . Toronto was close behind at 28 , but these recommendations to other levels of government comprised over $40 \%$ of Toronto's total recommendations. It is possible this emphasis on higher orders of government is a product of the size and influence of the City of Toronto. Vancouver's Drug Strategy, conducted by the largest city in British Columbia, contained 10 recommendations out of 31 (32\%) focused on the province and/or the Canadian government (MacPherson \& Rowley, 2001).

The recommendations to lobby provincial and/or federal levels of government typically focused on changing legislation related to crime and drugs, increases in funding generally, and increasing funding for programs, such as Ontario Works and youth employment programs. These recommendations also looked at changes to how correctional institutions operate, changes to existing regulations (such as changing Ontario Disability Support Program guidelines), and changes to the Ontario school curriculum.

\section{CONCLUSIONS}

The ten Ontario drug strategies reviewed had a number of commonalities, which can form the basis for municipalities to use in developing their own drug strategy. Each plan built upon the template provided by Vancouver's drug strategy. All of the municipalities used the four pillars of Prevention, Treatment, Enforcement, and Harm Reduction. Four municipalities added a pillar to their plans: Integration, Sustaining Relationships, or Housing.

The ten Ontario drug strategies used similar methods to gather data for their plans. All of the strategies reviewed existing local reports and/or local statistical data to form the basis of a plan. Every municipality reviewed, except for Peterborough, held at least one community forum as part of the plan. A majority of municipalities conducted focus groups and surveys. In addition, three municipalities conducted interviews as part of their plan.

These consultations led to recommendations addressing a wide variety of substance use and addictions issues. The plan recommendations lend themselves to creating a template of 10 questions for future municipalities to consider in their own consultations:

What are the overarching goals of the drug strategy?

How will the drug strategy be implemented?

Should the municipality change any of its policies or approaches for dealing with individuals facing addictions issues?

What changes are needed to existing programs to make them more effective?

- Are new programs needed to deliver additional services for those using substances?

Are there issues that require further research?

What promotional campaigns are needed to build public support for the plan and understanding of the issues related to substance use?

What are the training needs of the community with respect to substance use issues?

- How can the approach of law enforcement be more effective when addressing substance use issues?

- What changes should the provincial and federal governments initiate?

Exploring these questions by engaging people with general and firsthand knowledge of substance use issues in a community will provide key data for a municipality exploring its own drug strategy.

\section{ACKNOWLEDGMENTS}

Thank you to the Municipal Drug Strategy Co-orindator's Network of Ontario, who helped me find some of the Drug Strategies referenced in this report.

CONFLICT OF INTEREST DISCLOSURES

The author declares that there are no conflicts of interest. 


\section{AUTHOR AFFILIATIONS}

*Safe Brantford Administrator, City of Brantford, Brantford, ON, Canada.

\section{REFERENCES}

Alexander, B. K. (2006). Beyond Vancouver's "four pillars". International Journal of Drug Policy, 17(2), 118-123.

Chang-Yen Phillips, C, Cockburn, A., Kidd, M. and Knight, J. (2011). Building the Four Pillars: Approaches for meaningful and effective community participation in the Peterborough Drug Strategy's consultation process. Peterborough, ON: Trent University.

City of Toronto. (2005). The Toronto drug strategy: A comprehensive approach to alcohol and other drugs. Toronto, ON: Author.

Federation of Canadian Municipalities. (2000). Municipal drug strategies in Canada: A framework for developing a model municipal drug strategy. Ottawa, ON: Author.

Federation of Canadian Municipalities. (n.d.) FCM municipal drug strategy phase III Report: A Summary Evaluation of Pilot Projects. Ottawa, ON: Author.

Janzen, R. (2013a, April). Drug strategy accommodation needs assessment: Background research report. Thunder Bay, ON: Centre for Community Based Research.

Janzen, R. (2013b, May). Drug strategy accommodation needs assessment: A community plan for Thunder Bay. Thunder Bay, ON: Centre for Community Based Research.

Kenora Substance Abuse and Mental Health Taskforce. (2015). Kenora community safety and well-being plan. Kenora, ON: Author.

MacPherson, D. \& Rowley, M. (2001). A Framework for Action: A Four Pillar Approach to Drug Problems in Vancouver. Vancouver, BC: City of Vancouver.

MacPherson, D, Mulla, Z., \& Richardson, L. (2006). The evolution of drug policy in Vancouver, Canada: Strategies for preventing harm from psychoactive substance abuse. International Journal of Drug Policy, 17(2), 127-132.
MacPherson, D., Mulla, Z., Richardson, L. \& Beer, T. (2005). Preventing harm from psychoactive substance use. Vancouver, BC: City of Vancouver Drug Policy Program.

Osborn, B. and Small, W. (2006). "Speaking truth to power": The role of drug users in influencing municipal drug policy. International Journal of Drug Policy, 17(2), 70-72

Peterborough Drug Strategy Committee. (2012). Building the foundation for wellness: A strategic plan. Peterborough, ON: Author.

Pierce, S. (2008). Environmental scan-Needs assessment report. Guelph, ON: The Guelph Wellington Substance Abuse Strategy Committee.

Region of Halton. (2014). Counting, caring, growing: Laying the foundation for a Halton drug strategy. Halton, ON: Author.

Saad, D. (2013). Report to North Bay and Area Drug Strategy Committee Re: province of Ontario grant, Ministry Tourism, Culture \& Sport. North Bay, ON: North Bay and Area Drug Strategy Committee.

Sudbury \& District Health Unit. (2015). Community Drug Strategy for the City of Greater Sudbury: A Call to Action. Sudbury, ON: Author.

Thunder Bay Drug Strategy Committee. (2011). Roadmap for change: Towards a safe and healthy community. Thunder Bay, ON: Author.

Thunder Bay Drug Strategy Committee. (2013). Travelling the road to change. Thunder Bay, ON: Author.

United Way of Chatham-Kent. (2009). Working towards a framework for a drug strategy for Chatham-Kent: A community impact initiative. Chatham, ON: Author.

Waterloo Region Crime Prevention Council. (2011). Waterloo Region integrated drugs strategy. Kitchener, ON: Author.

Wellington Guelph Drug Strategy Committee. (2011). Strategies to reduce the impact of substance misuse in Guelph \& Wellington County. Guelph, ON: Author. 